\title{
Correction to: Electrical and Structural Characterization of Poly(3-hexylthiophene)-Polydiphenylamine Blends Synthesized on Various Conductive Substrates
}

\author{
Mayara Masae Kubota ${ }^{1} \cdot$ Henrique de Santana ${ }^{1}$
}

Published online: 21 April 2021

(c) The Minerals, Metals \& Materials Society 2021

\section{Correction to: \\ Journal of Electronic Materials, Vol. 50, No. 3, 2021 \\ https://doi.org/10.1007/s11664-020-08685-8}

In the original online version of the article the copyright holder was incorrect. The original article has been corrected.
Publisher's Note Springer Nature remains neutral with regard to jurisdictional claims in published maps and institutional affiliations.

The original article can be found online at https://doi.org/10.1007/ s11664-020-08685-8.

Henrique de Santana

hensan@uel.br

1 Departamento de Química, CCE, Universidade Estadual de Londrina, Londrina, PR 86051-990, Brazil 